

Jurnal Abdidas Volume 2 Nomor 6 Tahun 2021 Halaman 1374 - 1379

JURNAL ABDIDAS

http://abdidas.org/index.php/abdidas



\title{
Pelatihan Branding Sosialisasi Bank Sampah Merauke
}

\author{
Karlina Wong Lieung ${ }^{1 凶}$, Dewi Puji Rahayu ${ }^{2}$, Hanova Rani Eka Retnaningtyas ${ }^{3}$ \\ Pendidikan Guru Sekolah Dasar, Universitas Musamus, Indonesia ${ }^{1,2}$ \\ Pendidikan Bahasa dan Sastra Indonesia, Universitas Musamus, Indonesia ${ }^{3}$ \\ E-mail : lieung@unmus.ac.id ${ }^{1}$ rahayu@unmus.ac.id ${ }^{2}$, retnaningtyas@unmus.ac.id ${ }^{3}$
}

\begin{abstract}
Abstrak
Aspek teknologi merupakan salah satu hal penting yang perlu diaplikasikan dalam setiap kegiatan, mengingat semakin cepatnya perkembangan jaman yang menuntut segala hal mengikuti perkembangan teknologi. Bank Sampah "Prajurit Mandiri" Merauke merupakan salah satu kelompok yang peka terhadap isu sosial tentang pengolahan limbah sampah masyarakat, mengingat semakin besarnya jumlah penduduk, semakin besar pula limbah yang dihasilkan. Bank Sampah "Prajurit Mandiri" hadir untuk mengatasi masalah tersebut, namun dalam perjalanannya tidak mudah untuk dikenal oleh masyarakat khususnya masyarakat Kota Merauke, sehingga kampanye sosial untuk pengolahan limbah sampah masih belum dapat dilakukan secara efektif. Pelatihan branding sosialisasi Bank Sampah merupakan salah satu cara untuk meningkatkan animo masyarakat tentang pengolahan sampah dan mengenalkan masyarakat Kota Merauke eksistensi dari Bank Sampah itu sendiri. Dalam pelatihan ini, Tim dari Universitas Musamus mengajarkan pembuatan video promosi sekaligus teknik dasar editing serta promosi di media sosial. Jumlah interaksi postingan video selama 30 hari masa promosi menunjukkan angka 36.394 interaksi dari pengguna Facebook, dan berdampak pada meningkatnya jumlah nasabah di Bank Sampah "Prajurit Mandiri" Merauke. Dari hasil promosi video yang telah dilakukan, jumlah nasabah Bank Sampah meningkat dari semula sebanyak 83 orang, menjadi 112 orang dan terus bertambah.
\end{abstract}

Kata kunci: Facebook, promosi, video, bank sampah

\begin{abstract}
he technological aspect is one of the important things that needs to be applied in every activity, given the increasingly rapid development of the era that demands that everything follow technological developments. The Merauke "Prajurit Mandiri" Waste Bank is one of the groups that is sensitive to social issues regarding community waste management, considering the increase in population, the greater the waste generated. The Mandiri Prajurit Waste Bank is here to solve this problem, but along the way it is not easy to be recognized by the public, especially the people of Merauke City, so that social campaigns for waste management cannot be carried out effectively. The training on the socialization of the Waste Bank brand is one way to increase public interest in waste management and introduce the people of Merauke City to the existence of the Waste Bank itself. In this training, the team from Musamus University taught the making of promotional videos as well as basic editing and promotion techniques on social media. The number of video interactions during the 30-day promotional period shows 36,394 interactions from Facebook users, and has an impact on the number of customers at Merauke's "Prajurit Mandiri" Waste Bank. From the results of video promotions that have been carried out, the number of Waste Bank customers has increased from 83 people to 112 people and continues to grow.
\end{abstract}

Keywords: Facebook, promotion, video, waste bank

Copyright (c) 2021 Karlina Wong Lieung, Dewi Puji Rahayu, Hanova Rani Eka Retnaningtyas

\begin{tabular}{ll}
\hline$\square$ Corresponding author \\
Address & $:$ Universitas Musamus \\
Email & $:$ lieung@unmus.ac.id \\
DOI & $:$ https://doi.org/10.31004/abdidas.v2i6.496
\end{tabular}

ISSN 2721-9224 (Media Cetak)

ISSN 2721- 9216 (Media Online)

Jurnal Abdidas Vol 2 No 6 Tahun 2021 p-ISSN 2721-9224 e-ISSN 2721-9216 
1375 Pelatihan Branding Sosialisasi Bank Sampah Merauke - Karlina Wong Lieung, Dewi Puji Rahayu, Hanova Rani Eka Retnaningtyas

DOI: https://doi.org/10.31004/abdidas.v2i6.496

\section{PENDAHULUAN}

Bank sampah hadir sebagai alternatif solusi dalam upaya pengolahan sampah. Sampah akan selalu hadir sebagai konsekuensi atau buah aktivitas manusia dan jumlahnya akan terus bertambah seiring berkembangnya gaya hidup konsumtif masyarakat (Suryani, 2016:71). Kehadiran bank sampah dapat memberikan sumbangsih berarti bagi pemecahan masalah terkait dengan sampah. Meskipun kontribusi dari daur ulang sampah masih rendah, tetapi peranan bang sampah dalam hal memberikan edukasi bagi masyarakat sangatlah penting (Setiawan, 2021). Permasalahan sampah juga dialami oleh kabupaten Merauke. Terhitung awal tahun 2020 saja, jumlah sampah meningkat 200 kali lipat sejak tahun 2000. Rata-rata masyarakat Merauke membuang sampah 45-50 ton dalam sehari, ini hanya yang terhitung berlangganan sampah, sedangkan masih ada banyak masyarakat yang membuang sampah sembarangan (Kusnadi, 2021). Bank Sampah Prajurit Mandiri hadir sebagai salah satu kelompok yang mampu menjadi alternatif solusi mengelolaan sampah. Bank Sampah Prajurit Mandiri telah beroperasi sejak tahun 2019. Bank sampah ini merupakan bank sampah yang dibentuk secara mandiri dengan Surat Keputusan Nomor: 660/08/MDL/II/2019 yang diputuskan oleh Lurah Mandala tentang Pembentukan Pengurus Bank Sampah "Prajurit Mandiri”.

Bank sampah ini memiliki kantor di jalan Prajurit 2 RT 17 RW 04, kelurahan Mandala, Distrik Merauke dengan status sewa. Dalam pelaksanaan kegiatan, terdapat beberapa pengurus diketuai oleh ibu Indayati yang bekerja dalam hal manajemen, pengumpulan sampah, pengolahan hingga pemasaran. Pemberdayaan warga sangat penting untuk dilakukan. Kegiatan penyuluhan, edukasi, interaksi dan komunikasi, serta dialog dengan warga di komunitas harus dilakuakn secara berkesinambungan. Selain itu diperlukan dukungan kemitraan dengan membangun jejaring dan mekanisme kerja sama kelembagaan antara warga pengelola bank sampah dengan stakeholder terkait (Asteria, 2016:136). Sejak awal tahun 2021, bank sampah sudah difasilitasi armada berupa kendaraan roda tiga untuk dapat mengangkut sampah dari para nasabah. Hanya saja, para pengurus masih kesulitan dalam menambah jumlah nasabah dikarenakan sosialisasi lisan dirasa masih belum cukup efektif. Jumlah nasabah yang menabung sampah jelas diperlukan.

Semakin banyak nasabah yang menabung sampah, dapat memberikan beberapa keuntungan yang sangat diharapkan dapat dicapai diantaranya: a. Jumlah sampah yang terserap dan diolah akan semakin banyak sehingga dapat membantu dalam upaya pelestarian lingkungan; b. Kesejahteraan masyarakat terutama nasabah akan meningkat; serta c. Pelaksanaan operasional bank sampah dapat berkembang lebih pesat. Hal ini juga yang telah terjadi pada Bank Sampah Margasari. Meskipun secara dampak pemberdayaan masih kurang tetapi dalam hal sosial, bank sampah telah terbukti dapat menciptakan lingkungan bersih, meningkatnya kualitas kesehatan dan meningkatkan aktivitas gotong royong di masyarakat (Wardany, 2016:371). Maka dari itu diperlukan upaya sosialisasi dan promosi yang lebih efektif dapat menjangkau masyarakat luas 
1376 Pelatihan Branding Sosialisasi Bank Sampah Merauke - Karlina Wong Lieung, Dewi Puji Rahayu, Hanova Rani Eka Retnaningtyas

DOI: https://doi.org/10.31004/abdidas.v2i6.496

dengan cara-cara yang lebih efektif dan efisien.

Upaya tersebut berupa upaya-upaya untuk membekali para pengurus mengenai pentingnya branding, sosialisasi serta promosi dengan caracara yang efektif agar bank sampah dapat lebih dikenal masyarakat luas. Sosialisasi dan promosi juga dapat dikemas dengan cara-cara menarik yang dapat membuat masyarakat tertarik serta bersemangat untuk aktif menjadi nasabah yang menabung sampah.

Aspek teknologi sangat penting diaplikasikan pada mitra terkait dengan sosialisasi dan promosi bank sampah agar dapat menjangkau masyarakat yang lebih luas. Pelaksanaan pengabdian ini didasari oleh beberapa permasalahan mitra yang diuraikan sebagai berikut. a. Kurangnya teknologi yang membantu sosialisasi kepada masyarakat. b. Kurangnya penyebaran informasi terkait citra (branding) bank sampah. c. Kurangnya nasabah yang menyebabkan sampah yang terkumpul juga masih sedikit. Dengan jumlah sampah yang masih sedikit menyebabkan peran bank sampah belum terasa secara signifikan. Bank sampah yang memiliki tujuan salah satunya melestarikan lingkungan dengan cara pengelolaan sampah masih belum tercapai.

\section{METODE}

Mitra dari kegiatan pengabdian ini yaitu Bank Sampah Mandiri Merauke yang merupakan salah satu badan usaha yang dilaksanakan oleh beberapa orang pengurus yang diketuai ibu Indayati. Kegiatan utama bank sampah yakni terkait pengelolaan beberapa jenis sampah seperti besi, kardus, kertas, limbah minyak, plastik seperti ember, gen miyal dan sebagainya. Dengan beberapa permasalahan yang dihadapi ditawarkanlah solusi yang dapat dicapai dengan langkahlangkah kegiatan pengabdian sebagai berikut.

\section{Sosialisasi Program Kegiatan}

Kegiatan ini merupakan kegiatan awal dimana tim pengabdian melakukan komunikasi awal dengan mitra dan masyarakat setempat. Kegiatan ini direncanakan akan dihadiri oleh tim pengabdian, seluruh pengurus bank sampah, ketua Lurah Mandala, Ketua RT, tokoh masyarakat dan masyarakat yang ada di sekitar lokasi. Agenda utama pada tahap ini ialah memberikan informasi awal mengenai kegiatan yang akan dilakukan tim pengabdian, penjelasan mengenai manfaat kegiatan, dan langkah-langkah kegiatan selanjutnya untuk mencapai tujuan yang diharapkan.

\section{Persiapan Kegiatan}

Pada kegiatan ini, tim pengabdian mempersiapkan berbagai hal diantaranya materi pelatihan dan menghadirkan tokoh ahli dalam teknologi terkait dengan branding dan sebagainya. Menyiapkan bahan-bahan untuk pelatihan dan bahan untuk menyempurnakan sistem administrasi pada bank sampah.

\section{Kegiatan Pelatihan Dan Pendampingan}

Kegiatan ini berisi kegiatan pelatihan membuat branding dalam bentuk video, brosur, iklan dan sebagainya. Pada kegiatan ini, tim pengabdian dibantu nara sumber akan memberikan informasi mengenai berbagai jenis aplikasi yang bias digunakan untuk memberkuat branding bank 
1377 Pelatihan Branding Sosialisasi Bank Sampah Merauke - Karlina Wong Lieung, Dewi Puji Rahayu, Hanova Rani Eka Retnaningtyas

DOI: https://doi.org/10.31004/abdidas.v2i6.496

sampah diantaranya dengan membuat video pendek yang menarik sebagai media melakukan sosialisasi bank sampah. Video yang dibuat akan diunggah pada berbagai media sosial. Untuk memperluas jangkauan masyarakat, video tersebut juga akan di-iklankan pada media sosial Facebook, pemilihan Facebook untuk media iklan karena masyarakat Merauke merupakan pengguna Facebook yang sangat aktif. Ini akan membantu bank sampah menjagkau masyarakat Merauke lebih luas. Selain pembuatan video, pada pelatihan ini juga mitra akan dilatih dan dibimbing memperkuat branding dengan cara lain misalnya dengan membuat brosur. Pelatihan mengenai hal ini diperlukan untuk menambah softskill para pengurus bank sampah agar kedepannya mitra semakin dikenal dengan adanya sosialisasi yang terus menerus.

\section{Publikasi dan promosi}

Publikasi dan promosi dilakukan dengan menyebarluaskan video, brosur dan juga publikasi pada media cetak untuk menjangkau masyarakat yang lebih luas.

\section{Monitoring}

Monitoring dilakukan terhadap beberapa aspek diantaranya memonitoring perkembangan program yang telah dilaksanakan, mengidentifikasi kendala yang dihadapi dalam pelaksanaan program pengabdian ini, serta mencari solusi yang tepat dari permasalahan yang muncul agar segera dapat diperbaiki dan program ini dapat memberikan manfaat yang maksimal bagi mitra program yakni bank sampah mandiri.

\section{Evaluasi Program}

Evaluasi program ditujukan untuk mengetahui seberapa jauh keberhasilan dari kegiatan yang telah dilakukan. Indikator yang nanti dilihat adalah dari target yang telah ditetapkan sebelumnya. Selain itu evaluasi diperlukan juga untuk mengetahui kekurangan dari kegiatan pengabdian yang telah dilaksanakan agar kedepannya dapat segera diperbaiki lagi. Kegiatan ini dilakukan oleh tim pengabdian bersama-sama dengan Lurah Mandala, pengurusa bank sampah, tokoh masyarakat dan pihak lain yang berkepentingan. Kegiatan evaluasi diharapkan mampu memberikan masukan bagi penyempurnaan kegiatan ini agar lebih baik lagi.

\section{HASIL DAN PEMBAHASAN}

Kegiatan pengabdian dilaksanakan dengan rincian kegiatan sebagai berikut.

\section{Sosialisasi Program Kegiatan}

Sosialisasi dilakukan pada fokus pembahasan mengenai pentingnya melakukan branding sebagai upaya sosialisasi yang efektif. Lalu dilanjutkan dengan pendampingan pengambilan gambar video. Setelah gambar diambil, maka akan ada proses editing dan membuat iklan di media sosial Facebook. Dampak dari iklan yang dibuat kemudian akan dimonitoring setelah itu evaluasi akan satu bulan setelahnya.

\section{Persiapan Kegiatan}

Persiapan yang dilakukan tim meliputi menyiapkan baliho kegiatan, menyiapkan alat dan bahan untuk membuat video serta tentunya untuk 
1378 Pelatihan Branding Sosialisasi Bank Sampah Merauke - Karlina Wong Lieung, Dewi Puji Rahayu, Hanova Rani Eka Retnaningtyas

DOI: https://doi.org/10.31004/abdidas.v2i6.496

memberikan materi mengenai pembuatan video dibantu oleh nara sumber yang dipersiapkan tim.

\section{Kegiatan Pelatihan Dan Pendampingan}

Sesuai rencana yang diuraikan sebelumnya, kegiatan ini diisi dengan pelatihan membuat branding dalam bentuk video, dan iklan. Pada kegiatan ini, tim pengabdian dibantu nara sumber memberikan informasi mengenai berbagai jenis aplikasi yang bisa digunakan untuk memberkuat branding bank sampah. Pembuatan video melibatkan pengurus bank sampah dan tim pengabdian. Proses editing video melibatkan pengurus bank sampah, tim pengabdian dan tokoh ahli. Selanjutnya para pengurus bank sampah didampingi dalam memasang iklan di media social Facebook. Sambil melakukan monitoring terhadap iklan yang telah terpasang, tim juga melakukan pendampingan dari segi administrasi bank sampah.

\section{Publikasi dan Promosi}

Publikasi dan promosi ini meliputi kegiatan memasang iklan pada media sosial Facebook. Hasil dari publikasi dan promosi sudah mulai terasa dengan meningkatnya jumlah nasabah serta jumlah sampah yang tertabung di bank sampah.

\section{Monitoring}

Kegiatan yang telah dilakukan telah memberikan dampak yang cukup baik bagi peningkatan softskill pengurus bank sampah dalam melakukan branding bank sampah, serta sudah menunjukkan peningkatan nasabah dari sebelumnya. Meskipun ada keterbatasan dari pengurus bank sampah dalam menerima seluruh karena terkendala armada dan tenaga, namun tim pengabdian optimis kegiatan ini akan tetap dijalankan karena para pengurus telah aktif.

Interaksi postingan di Fanpage Facebook

Bank Sampah "Prajurit Mandiri" Merauke meningkat secara signifikan dari postingan biasa tanpa promosi yang biasanya rata-rata hanya menjangkau sekitar 30 pengguna Facebook, setelah dilakukan promosi dan dibuat video yang representatif dan menarik, meningkat sebanyak 36.395 interaksi dari pengguna Facebook di Kota Merauke. Dengan jangkauan masyarakat yang semakin luas, sudah barang tentu samkin banyak masyarakat yang tahu eksistensi Bank Sampah di Merauke, sehingga semakin bertambah pula Nasabah yang ingin bergabung bersama dengan Bank Sampah "Prajurit Mandiri” Merauke. Jumlah total nasabah sebelum dilakukan branding dan promosi sebanyak 83 orang, sedangkan setelah dilakukan promosi meningkat hingga 112 orang,. Hal tersebut menunjukkan efektivitas branding Bank Sampah dengan menggunakan Video dan Promosi di Media Sosial Facebook.

\section{Evaluasi Program}

Program yang dilaksanakan telah dievaluasi bersama dan memperoleh hasil yang sangat baik. Setelah adanya video dan iklan, jumlah nasabah terus meningkat dan masih banyak juga nasabah yang mengirim pesan pada pengurus untuk mendaftar menjadi nasabah. Hanya saja, pengurus masih kesulitan menjangkau seluruh calon nasabah karena keterbatasan armada. Permasalahan ini memang sering klai dialami oleh bank sampah lain di Indonesia. Salah satunya bank sampah Maspro Mesra di Kota Probolinggo. Permaslaahan yang dialami serupa, yakni, peminat banyak, tetapi 
1379 Pelatihan Branding Sosialisasi Bank Sampah Merauke - Karlina Wong Lieung, Dewi Puji Rahayu, Hanova Rani Eka Retnaningtyas

DOI: https://doi.org/10.31004/abdidas.v2i6.496

program bank sampah mengalami hambatan dalam mencapai daerah pelosok (Shentika, 2016:99). Artinya sosialisasi masih perlu diperluas. Maka penambahan nasabah masih terus dilakukan secara bertahap.

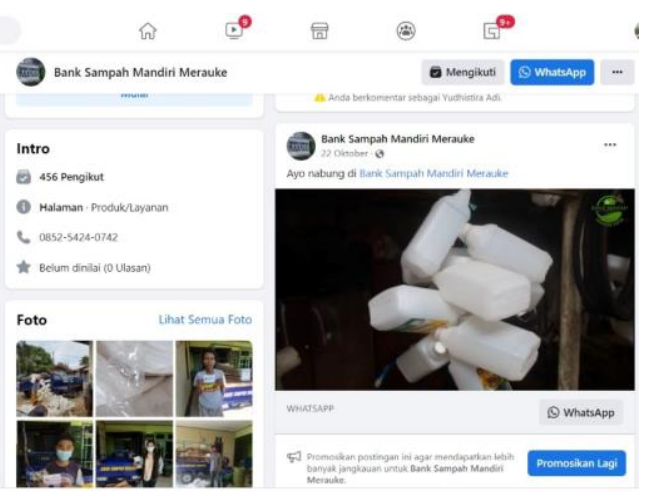

Gambar 1. Postingan Video Promosi Bank Sampah


Gambar 2. Nasabah Baru Setelah Adanya Promosi

\section{SIMPULAN}

Kegiatan Pengabdian Pendampingan

Branding Sosialisasi Bank Sampah memberikan hasil yang sesuai dengan rencana dibuktikan dengan penambahan jumlah nasabah yang bergabung kedalam Bank Sampah "Prajurit Mandiri" Merauke.

\section{UCAPAN TERIMA KASIH}

Terima kasih kepada Universitas Musamus melalui Lembaga Penelitian dan Pengabdian Masyarakat (LPPM) yang telah mendukung terlaksananya kegiatan pengabdian dan penerbitan artikel ini.,

\section{DAFTAR PUSTAKA}

Asteria, Donna \& Heruman, Heru. 2016. BANK SAMPAH SEBAGAI ALTERNATIF STRATEGI PENGELOLAAN SAMPAH BERBASIS MASYARAKAT DI TASIKMALAYA (Bank Sampah (Waste Banks) as an Alternative of CommunityBased Waste Management Strategy in Tasikmalaya). Jurnal Manusia dan Lingkungan. Vol. 23 (1) hlm. 136-141. https://doi.org/10.22146/jml.18783

Shentika, Prisa Ambar. Pengelolaan Bank Sampah di Kota Probolinggo. JESP. Vol 8 (1) hlm. 92-100.

https://core.ac.uk/download/pdf/296853416. pdf

Suryani, Anih Sri. 2014. Peran Bank Sampah dalam Efektivitas Pengelolaan Sampah (Studi Kasus Bank Sampah Malang). Jurnal Aspirasi. Vol. 5 (1) hlm. 71-84. http://jurnal.dpr.go.id/index.php/aspirasi/arti cle/view/447

Kusuma Wardany, Reni Permata Sari, \& Erni Mariana. (2020). Sosialisasi Pendirian "Bank Sampah" Bagi Peningkatan Pendapatan Dan Pemberdayaan Perempuan Di Margasari. Dinamisia : Jurnal Pengabdian Kepada Masyarakat, 4(2), 364372.

https://doi.org/10.31849/dinamisia.v4i2.434 8

"Volume Sampah di Kota Merauke Capai 50 Ton Sehari”. Tersedia: shorturl.at/tEGHZ [online]. Diakses 14 Desember 2021.

"Membenahi Tata Kelola Sampah Nasional. Tersedia: shorturl.at/enuD9 [online]. Diakses: 14 Desember 2021. 